Entrepreneurship

ISSN: 2738-7402

DOI: 10.37708/ep.swu.v8i2.4

Volume: VIII, Issue: 2, Year: 2020, pp. 35-42

\title{
STRATEGIC SUSTAINABILITY OF THE ORGANIZATION. STRATEGIC CUBE OR STRATEGIC STATUS MODEL OF THE ORGANIZATION
}

\author{
Temenuzhka Karolova Chromy -Zhigalova ${ }^{1}$
}

Received: 07.10.2020, Accepted: 27.10.2020

\section{Abstract}

The strategic sustainability of the organization is determined by the three main components of the strategy that characterize its activities. Three main points of the activity of the organization - economic, political and organizational are integral parts, they form the basis on which the management of the company is built in modern economic conditions. This article analyzes the first component of the organization's strategy.

What balance of political, economic and organizational aspects ensure the best conditions of the company? Revealing the meaning of each of them, it should be borne in mind that the good situation of one or two positions is not sufficient for the stability of the company: a balanced development of all aspects is needed.

Keywords: Model, strategic sustainability, efficient and strategic management, economic transformation

JEL Codes: D 210

\section{Introduction}

Improving the management system of the enterprise or organization can be achieved by using different approaches. One of them is the model of the strategic state of the organization or strategic cube. It can be assumed that the work of each company depends on the state of the following three components: economic, political and organizational. (Vikhanski, 2006).

1 "Neophyte Rilski" South-West University, Blagoevgrad, Bulgaria Department of Economics, Assoc. prof., PhD, e-mail: tkarolova@swu.bg, ORCID ID: https://orcid.org/0000-0001-9436-4240; 


\section{Economic aspect of the strategic condition of the organization.}

In general, the essence of the economic aspect depends on solving four main issues:

- What does the company want?

- What is its current status?

"What does it want to do?"

"What will the company do?"

These four questions, built in a logical sequence, express the way of thinking of the decision-maker. If we consider this analytical process of economic aspect assessment in greater details, we will find out that it is comprised of the thorough identification and study of the following issues.

\section{What does the organization want?}

Upon defining the strategic business zone (strategic work area), the mission and goals of the company, developing the portfolio of types of activities, the first question can be answered: "What does it want?".

1. To determine the strategic economic zone (GCC), ie. these types of activities in terms of products - a market that coincides with the strategy point. For example, the various $G C C s$ may be related to the production of small electrical appliances for general consumption, professional electronic equipment for TV sets or surgical products.

2. Formulating the mission of the organization, namely revealing the meaning of the existence of the organization and defining the field of activity. This means the way an enterprise defines its place in the economic, political, technological and social environment that surrounds it. For example, support for good self-esteem and health of the population.

3. Determination of quantitative and qualitative goals, which the company wants to reach for the planned period. For example, to increase turnover by $60 \%$ in 2 years and to become a leader in the industry by developing new goods.

4. Choice of portfolio by types of activities in which the company wants to be engaged in the future. For example, to have a balanced portfolio consisting of such activities that are booming and represent industries of the future, but are based on traditional goods, providing an inflow of funds that satisfy the company. 


\section{What is the organization at the moment?}

By analyzing the external environment, deviations from the planned indicators, the existing portfolio of activities and assessing the potential of the company, one can answer the second question: "What is the organization at the moment?".

1. Analysis of the external environment. It is a question of determining each $G C C$, secondly, identification of the main tendencies of development of the external environment in order to determine the probable dangers; then planning what needs to be done to succeed. For example, possibility of conquering a new market or danger of a new competitor.

2. Assessment of potential. This is an assessment of the totality of the existing funds, their advantages and disadvantages for each $G C C$, expert examination of each of them. For example, good production equipment, underdeveloped sales network, quality mark, competent human resources, uncertain financial condition of the company.

3. Study of the deviations from the planned indicators. There is usually a difference between what a company wants and what it actually represents which needs to be analyzed. Taking into account the development trends of the external environment and the state of the current company potential, its achievements are assessed provided nothing changes and it works as usually. For example, in three years the reached amount of BG 170 million Lev will be compared with the set target of BG 190 million Lev. The difference of BG 20 million Lev is a deviation that must be analyzed to determine the reasons.( Bankova,2019)

4. Analysis of the existing business portfolio. If the answer to the question: "What does the organization want?" - the desired portfolio by types of activities is meant, therefore the problem here is in the existing portfolio description and the analysis the differences between the desired and the actual one. For example, today's portfolio includes poorly profitable declining activities and types of activities approaching maturity but very profitable. It is necessary to change the content of the activity portfolio, namely to include new types of activities based on a previous but stable basis that corresponds to the available resources. 


\section{What does the organization want to do?}

After defining the strategic guidelines for development, the strategy analyzes their contribution to company goal achievement and mission, and the third question can be answered: "What does the organization want to do?".

1. Determining the strategic tendencies of development. Should any activity be maintained at its current level, or is it better to gradually abandon it or should it be oriented towards a new market or a new segment? For example, for electronic business companies, it must be decided whether to maintain the leading role in the production of a system of medical equipment (in the absence of a government contract), to discontinue the production of household appliances or to switch entirely to the creation of electronic components for high-tech lines.

2. Formulation (definition) of the strategy. The organization determines the global strategy of its development (corporate strategy), i.e. the strategy of each business unit (business strategies) on the basis of which the functional and operational strategies are developed. For example, the strategy of internationalization can be defined as a corporate strategy, and the strategy of differentiation can be defined as a business strategy for one of the divisions.

3. Evaluation of strategy and policy. This assessment refers to the analysis of the contribution of the strategy in the realization of the goals and mission of the organization, taking into account the limited resources available and the trends in the development of the external environment.

\section{What will the organization do?}

After choosing the strategy, developing the plan for its implementation, evaluating the future financial results and forming an adequate strategy for the management structure, the last question of the analytical process can be answered. "What will the organization do?"

1. Choice of strategists. It is about choosing a strategy and policies that will be adopted depending on the priorities of the organization. For example, focus efforts on developing new products or new types of activities.

2. Development of programs and work plans. Who should do what first and when? The organization faces similar issues when planning its activities. For example, should it first and foremost improve its position in those strategic economic zones (GCCs) that are in decline 
or should it focus on creating new products? Should it focus its efforts on development and at the same time prepare a marketing network for new GCCs until the results of marketing research are obtained? What action to take first?

3. Budgeting. Development of a financial plan and assessment of financial consequences of the accepted strategic choice. For example, what will be the additional income from the production of electrical components for high-tech lines and what will be the costs. What additional resources are needed to succeed in this business: production equipment, staff?

4. Search for a management system that is adequate to the strategy. What structure, what control, what planning what ways an organization must choose to give better chances for the success of the strategy? For example, will the company product structure be better than the functional structure? Will decentralized planning be preferred to centralized one? Will control have to relate only to the results, or will it also cover some tasks?

At the same time, when considering the above-listed questions, it is necessary to remember that it is more important to develop a mechanism for this process and ensure its functioning, rather than simply answering the questions raised. The simplified scheme of this process shows that it is cyclic and interactive. 
Figure no. 1. Scheme of the process of developing economic components of strategic state of the organization

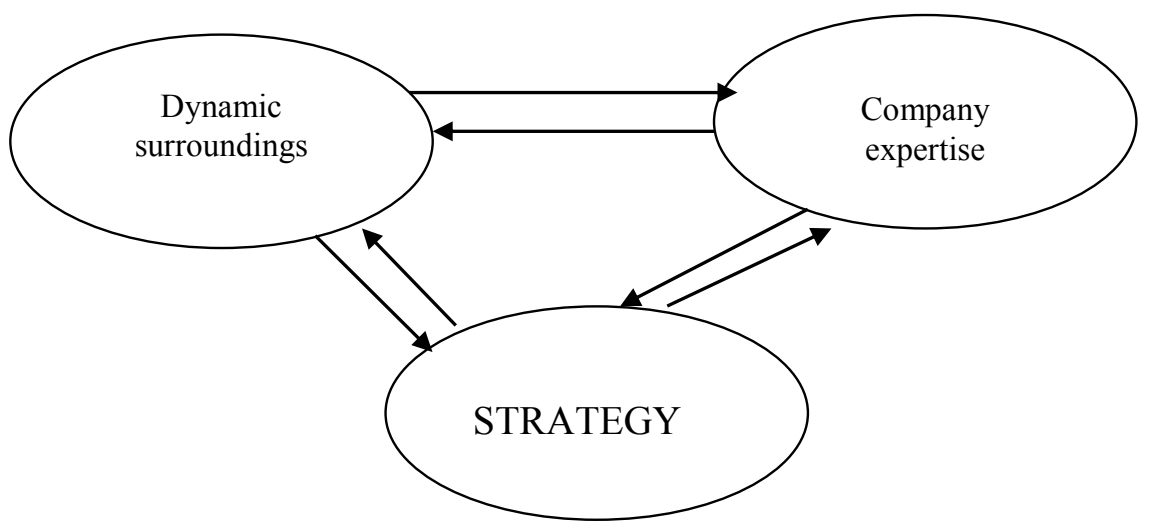

In fact, the process of developing the economic components of a company's strategic position is not linear and cannot be. Rather, it is about interactive processes that allow a solution to be reached gradually. This decision will be the result of comparing the dangers and opportunities offered by the external environment, the development strategy and the increased competencies of the staff. Of course, this comparison does not take place in such a direct form as presented above. There are usually numerous back and forth movements between each stage (Kiyosaki, 2019).

\section{Levels of strategic decision making}

There are several levels of strategic decision making in an organization. Each of these levels corresponds to different characteristics of the strategies. Indeed, the development of the economic aspects of the strategy at the level of the company's divisions (business strategy). The different scale of decisionmaking, the degree of compliance, is specific to strategic decision-making.

The top management of the organization usually addresses several of the most important issues - the mission and general goals of the company; the global vision of the common activities of the same; i.e. the content of its investment portfolio; the use the distinctive organizational and professional abilities of the staff; the study of the long-term competitive advantages of the organization; allocation of resources and efforts for different activities according to priorities; development of specific types of activities, different from the traditional ones, to correspond to the general development strategy. 
At senior management level, some of the above- described issues may have received more attention to the detriment of others. For example, the issues of mission formulation, setting goals, choosing the content of the investment portfolio, assessing the advantages and disadvantages of the industry in which the company is located, and analysis of competitiveness, deviation of achieved results may be of particular importance for the management of the planned indicators. While resolving the last three questions, new tasks arise. On one hand, it is a matter of seeking new areas of interest to the company if guided by the previous types of activities, it cannot reach the state to which it aspires, and, on the other hand, of setting strategic priorities that are not covered by the formal decision-making process, such as the search for suitable companies for possible mergers or their transformation (Ansoff, 1979).

At the business unit level, some other issues will be more important. The search for distinctive features and competitive advantages play a major role here, as well as the manifestation of energy between the types of activities and the functions needed to implement the strategy. Under these conditions, all efforts to implement the strategy are aimed at adapting the types of activities to the characteristics of the specific external environment, to the development of these activities in the market, to the selection of product nomenclature, research guidelines or production methods. (Karolova, 2003)

At the same time, at the level of the business unit the issues that are considered concern the development of the economic aspect of the strategy, considered at the level of senior management of the company (excluding definition of the mission and strategic goal of development of the whole company), but in more details. The issues that concern the choice of strategy, work program development and evaluation of activity financial results are added to the above-listed ones.

\section{Conclusion and Recommendations}

The process described is aimed mainly at seeking a gradual and integrated correspondence between resources, knowledge, experience, internal capabilities of the company on one hand, and the strategies that need to be changed in order to cope with the competition on the other hand. It is a formal process, which needs to take into account the political aspects of the company's activities, i.e. the respective strength of internal and external factors, otherwise they can either help to implement the strategy or hinder it. The next publication will present and analyze the political and organizational aspect of the strategic state of the organization. 


\section{REFERENCES}

Ansoff. I., Strategic Management. (1979). Igor Ansoff: Strategic Management. M., 1989. // Electronic publication: Center for Humanitarian Technologies. 2012.

Bankova, I., (2019). Dissonances and potentials in conflict management in project management, VFU University Publishing House "Chernorizets Hrabar" Varna, ISBN 978 -954-715-676-0, p.137

Anderson, J. C., Hoffman Th., A Perspective on the implementation of management Sciense, Academy of Management Review, July 19781 p.56 5

Karolova, T., (2003) Strategic management. The ability to lead a modern business, ed. Neofit Rilski ”, B1., p. 91-93

Karolova, T., (2003) Innovations and innovative development, published by SWU N. Rilski , Bl., p.29

Kiyosaki, R., Fleming J. \& Kiyosaki K., Business of the XXI Century, ed. Popurri, 2020

Kiyosaki, R., (2019) Goals and Solutions, Popurri Publishing,

Vasilev, V., Stefanova, D. \& Cherkezov, V. (2019) . Crisis Management, PROPELLER Publishing House, ISBN 978-954-392-567-4, p. 6

Vikhanski, O. S., Management, (2006) ed. Economist, M. 